\title{
DID.VALUE: A PROJECT FOCUSED ON DEVELOPING A HOLISTIC MODEL FOR INCLUSION OF DISADVANTAGED COMMUNITIES IN INTERNSHIPS AND JOBS
}

\author{
Maria Potes Barbas ${ }^{1}$, Pedro Matos ${ }^{2}$ \\ ${ }^{1}$ Escola Superior de Educação do Instituto Politécnico de Santarém (PORTUGAL) \\ ${ }^{2}$ Escola Superior de Educação do Instituto Politécnico de Santarém (PORTUGAL)
}

\begin{abstract}
As society keeps expanding and growing as a whole, tackling new challenges and disrupt alternatives in order to generate new jobs, educational offers, technological services, health and lifestyle opportunities and other aspects that constitute this large community, it is important to guarantee proper solutions and answers to the needs of those who are at a more disadvantaged background. In this case, we talk about people with disabilities or other communities who suffer from exclusion or face low opportunities scenarios. It is important to ensure that these groups can be included in society and be part of its several systems (employment, education, social affairs, equity, access to technologies, among other aspects).

Therefore, The DID. VALUE project is a European action, combining the strengths and experience of three main partner countries (Portugal, Croatia, Cyprus) and other associated partners, that seeks to define and implement a holistic model that facilitates, through disruptive methodologies, innovative integration methods and learning mechanisms adapted to the needs of young people with disabilities and other disadvantaged communities, the social and professional inclusion of these target groups towards internships and jobs. In this sense, this work will describe the processes and strategies that led this comprehensive and integrated model to a deeper understanding of how these target groups can be included in society and on its several layers of composition. This way, generating new knowledge and good practices on which methods and resources can be used as key guidelines to solve these problems in a systemic way.
\end{abstract}

Keywords: Holistic models, innovative methodologies, social inclusion, communities, people with disadvantaged backgrounds

\section{INTRODUCTION}

The motivation that drives the DID.VALUE project to be developed is based on several reasons. One of the main ones has to do with the dimension of Social Inclusion and the importance that this aspect has for the society in general. This project is seen as a facilitator of change, addressing the main priorities at national and European level. Therefore, this project intends to act as an agent for change in society, through non-formal training and by investing in an adapted and unique approach (holistic model for social and labor market inclusion), continuing to invest in strategies for social and labor inclusion. Whether through this project, or other initiatives or resources, the important thing is to provide and ensure adequate experiences for all types of participants who need better living conditions. Particularly for more specific target audiences, such as young people with intellectual and developmental difficulties that face several constraints and struggles in their daily lives. It is essential to reduce, in an effective, safe, and practical way, the challenges that lead to the emergence of new social barriers (such as discrimination, inequality, among others). In this sense, this project will also allow the leverage of the mission of a Higher Education Institution to something more ambitious. Thus, implementing actions with a mix of entities and stakeholders that, in partnership, implement new measures, support models, training offers, projects, initiatives and other means that confront social, educational, technological, and professional exclusion.

This said, according to several recent studies, particularly McMahon, Bowring \& Hatton[1] and Francis, Stride \& Reed[2] it is also known that one of the most care ambitions of people with an intellectual and developmental disability (IDD) is to have a paid work. However, according to Petner-Arrey, HowellMoneta and Lysaght[3], historically, yet, they have had high unemployment rates and nowadays continue to face barriers to attaining employment. Besides inclusion policies, there are several barriers to overcome to ensure the access of persons with IDD to the labor market. One of them is proper training to obtain competencies and skills in working. In addition, studies from Andersson, Luthra, 
Hurtig \& Tideman[4] indicate that previous experiences of employing persons with disabilities were linked to the greater intention of new hires. However, similar studies from Meltzer, Robinson \& Fisher[5] demonstrate that some employers point out as barriers the difficulty to design roles for employees with IDD, inadequate hiring procedures, employer's lack of knowledge regarding how to support employees with IDD and a perceived inadequate work environment to accommodate their needs.

Finally, and summarizing some of the most globally facts and priorities that this project aims at addressing, mostly related to societal issues are:

a) The fact that, according to the United Nations[6], Young people with disabilities are among the poorest and most marginalized of the world's youth. Estimates suggest that there are between 180 and 220 million youth with disabilities worldwide, and nearly 80 per cent of them live in developing countries.

b) Over one billion people or $15 \%$ of the world's population live with some form of disability, and of these, between 110 and 190 million have significant difficulties in functioning, according to the World Report on Disability[7].

c) Lack of skills and qualifications limits the employment opportunities for young people with disabilities[8].

d) At EU level, about $47 \%$ of persons with disabilities are employed, compared to $72 \%$ of persons without disabilities. The unemployment rate of people with disabilities in the EU, aged $20-64$, is $17 \%$ compared to $10 \%$ of persons without disabilities and the EU activity rate of persons with disabilities is $57 \%$ compared to $80 \%$ of non-disabled people[8].

Having identified its major challenges, this project aims to address them by developing an innovative and integrated holistic model capable to (a) connect and engage all the social actors that compose this ecosystem, (b) understand and meet the actors' and participants needs and expectations and (c) accelerate the effectiveness of methods, tools, and resources on digital literacy for social and labor market inclusion.

\section{AN OVERVIEW ON METHODOLOGIES}

The process of finding, adapting, and integrating a methodological framework in a project is a difficult task to perform at any time, specifically, when it comes to an action or strategy that involves several steps - research, observation, study, testing, prototyping, and completion. In addition, since it is a specific target audience (young people with disabilities and other disadvantaged communities), it implies that the methodology to be adopted can be adaptable and extensible to a set of work and variable operations. In this way, this integrating aspect is one of the determining factors to consider since it will measure the levels of success or failure of the methodological choice to be adopted. Authors such as Killeen \& O'Day[9] and Ann Block and Weatherford[10] justify the importance of a self-sufficient methodology, capable of subjective learning by different peers or stakeholders. In addition, they also indicate the high importance of a methodological spectrum that is based on a qualitative narrative in which, issues such as social constraints, social barriers, and other challenges such as prejudices, exclusions and other social factors are possible to observe, analyze and interpret.

This said, the DID. VALUE project seeks to define and implement a holistic model that facilitates, through disruptive methodology, innovative integration methods, learning mechanisms adapted to the needs of young people, among other aspects, the social and professional inclusion of young people with intellectual and developmental disabilities, regarding their entry and contact with the labor market, specifically with paid traineeships and jobs. In addition, the project team argues that the inclusion of this specific target group depends on their acquisition of digital literacy, communication and psychosocial skills and other job-specific competences. It also requires the engagement of different intervenient actors as family members, higher education institutions, potential employers, support agencies and regulatory institutions. It implies the need of a comprehensive and integrated model to understand the complexity of the person with disabilities and its relation to either employability issues and how can be created coordinated processes, methods, practices, resources, and policy recommendations that can tackle and solve these problems in a systemic way. In this sense, this methodological approach seeks to:

1. Enhance inclusive practices and initiatives, which involves several players or stakeholders and allow for young people with or without disabilities the possibility of acquiring a set of 
fundamental social, professional, and technical skills, promoting large-scaled know-how in this diverse context, as well as to provide adapted and quality traineeships and jobs, for the participants to understand working methods and gain their own autonomous experience of being in the labor market.

2. Strengthen excellence in the application of this model by engaging a set of the learning process, based on competencies frameworks, in digital literacy, social skills and professional and technical skills, as effective strategies for social and labor market inclusion.

3. Develop, prototype, and test an integrated inclusion support model that can be globally replicated by other institutions with practices, resources, methods in the digital literacy and ICT domains and connection processes to attain successful and sustainable social and labor inclusion.

The model to be designed will follow a specific framework in which will contemplate the following process and steps for fostering the social and professional inclusion of young people with disabilities:

a) Create processes for observation and monitoring of the entire social, professional, and technical ecosystem and develop a deep understanding of its actors' and participants needs, expectations and barriers.

b) Understand the required competences in the several domains of action (social inclusion, labor market inclusion, digital literacy, and other ICT competencies) that persons with IDD may achieve to attend those needs and expectations.

c) Establish and validate high-performing practices, methods, and resources, throughout the participants practice on the traineeships and jobs, to overcome barriers and attend the referred needs and expectations that result in positive employment outcome for people with disabilities and other disadvantaged communities.

d) Communicate and create strong and effective linkages across system actors that further maximize the social and labor market inclusion opportunities and improve employment outcomes for these target groups.

e) Developing support processes and recommend guidance and assistive technologies and tools to help all the actors to keep sustainable employability strategies to these communities.

f) Ensuring the model is built with sustainable principles and so can be replicable and available to other institutions supporting the social inclusion of persons with disabilities in the labor market.

Therefore, achieving a holistic model that can integrate these main pillars is one of the most important achievements on implementing a new and innovative holistic methodology. Especially, since the target group that is undergoing the research and all its related activities or actions are, majorly, young people with disabilities or other disadvantaged communities.

This said, it should be stressed that this holistic methodology approach must be open and validated by other players, entities, stakeholders, social institutions, etc., to allow a sustainable model replication for other interested parties that aim to put in practice this model with their desired participants. In addition, the model addresses the different factors that are critical for success, in terms of weight and role, to increase the probability of success and effectiveness in the social inclusion and employability of young people with disabilities, presenting recommendations not only for engagement and connection with the different actors but also for the design of new inclusive education policies.

\section{ACHIEVABLE OUTCOMES AND OTHER FINDINGS}

The DID.Value project and the proposed holistic methodology are still under development and the testing, prototyping and validation phase are planned after this initial phase. Thus, it is difficult to draw conclusions and initial results from either one aspect or another. However, after working and cooperating with a focus group of 7 senior researchers, 3 early career researchers, 2 interns, 10 inclusive education teachers and 13 students from Higher Education with disabilities or from disadvantaged communities who were attending a professional internship it was possible to conclude that: 
a) The importance of continuing training personalized and adapted to the social and educational needs of each participant, as one of the key factors for the success and inclusion of young people with disabilities in the labor market.

b) The value of having a digital medium (accessible to all and inclusive) in which everyone communicates, participates, and collaborates in different activities to promote open and flexible communication and support by different stakeholders.

c) The creation of a follow-up guide, also called Handbook on Training Modules, has become an essential tool for the participants' perception and learning. This guide gathers all information about the courses, programs, training, tools, and other aspects that the participants need to know before starting a training or professional activity. In addition, this guide includes step-bystep tutorials, video explanations, interactive applications and other resources that enhance each participant's curiosity and learning curve.

In addition, further findings were discovered that allowed the creation of a matrix. This matrix includes its own methodology that defined the following structure:

a) The personal learning matrix that appears in this research as PLM includes 3 levels of difficulty: basic level, intermediate level, and advanced level.

b) In each of these levels it is possible to find several learning topics, each of which is represented by a color. In this sense, the blue color represents the basic level where the following learning topics are found: (i) Social Skills; (ii) Working Relationships; (iii) Creative Skills. The Basic level modules allow the participants to get a more wide and general learning approach on their social, professional, and technical skills. Great for starters. Then, the pink color was defined, which represents the intermediate level and where the following learning topics are found: (i) Pedagogical Skills; (ii) Teamwork and Collaboration; (iii) Emotional Intelligence. The Intermediate level modules allow the participants to get a more specific and focused learning approach on their social, professional, and technical skills. Great for more advanced participants. Finally, the orange color which represents the advanced level and has the following learning topics: (i) Digital Literacy Skills; (ii) Community Building and Networking; (iii) Cultural Awareness. It is understood that the Advanced level modules allow the participants to get a more challenging and specific learning approach on their social, professional, and technical skills. Great for more independent and autonomous participants.

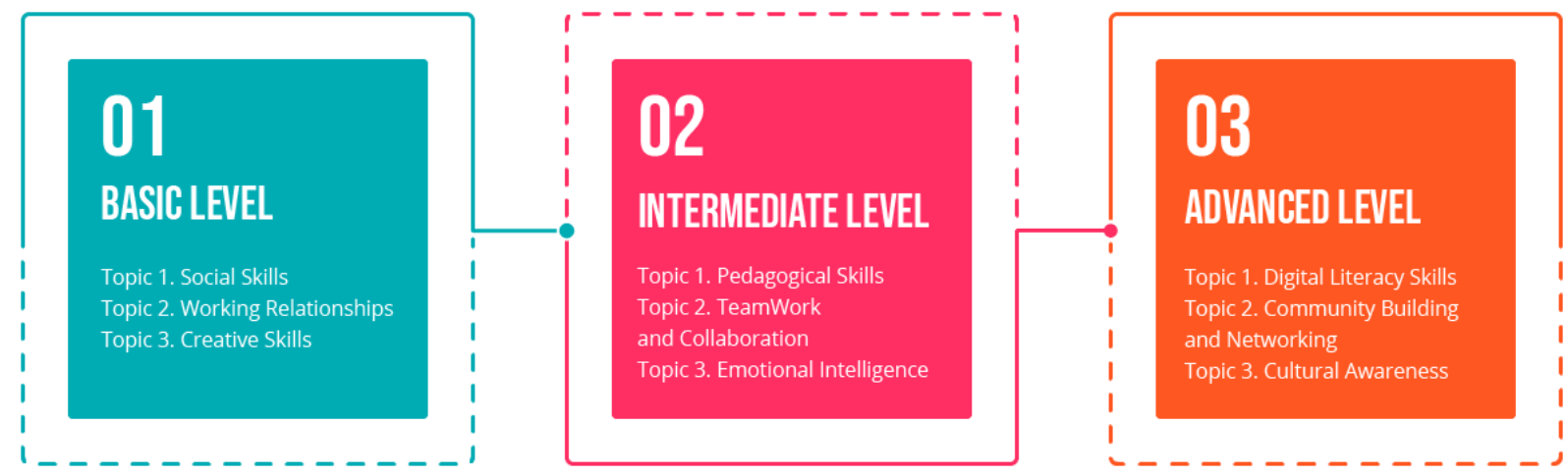

Figure 1. Matrix Levels of the Holistic Model

Once again, it is important to mention that these initial findings were obtained through the focus group indicated above. Some of the learning topics may change depending on the needs of each participant and even their social, professional, and technological background.

\section{CONCLUSIONS}

One of the first conclusions that can be drawn from this project and the respective implementation of an innovative and holistic methodology is the Inclusion factor and what it represents for the success of this strategy. Thus, it is important to understand that this project intends to respond to other needs, 
specifically, to broaden the impacted target group and fully address other needs and other types of disadvantageous situations (such as: geographically displaced, poor, with cognitive difficulties and facing other types of social constraints) that also emerge as recurring social issues. It is essential that by tackling the different steps of design, development, and implementation of this holistic model it fully includes the "Social Inclusion" phenomenon as a focal point of guidance and best practice. Since one of the pillars that this project intends to disseminate is the fact that it allows for a holistic model that is reviewed in a solid inclusive strategy. Therefore, one of the main aims of this project is enabling new scenarios in which it is possible to allocate disadvantaged young people and target audiences from less advantageous social scenarios in sustainable contexts of traineeships and jobs.

As for other conclusions, it is important to highlight the definition of the Matrix Levels of the Holistic Model. Firstly, because it allowed for a more organized and linear structuring of the various levels of learning that can be achieved within the holistic model. Thus, by defining three levels of difficulty: basic, intermediate, and advanced, it allows greater flexibility for the participant, guaranteeing an approach more adapted to their social, cultural, and pedagogical needs. In another aspect, when realizing that each level of difficulty has its own learning topics, the participant covers a set of multidisciplinary and transversal subjects, skills, and knowledge. Addressing both hard and soft skills, being these, essential tools for successful inclusion in the job market. Finally, this latest finding allowed us to understand which modules are most relevant for a robust, intuitive, and paced learning by each participant, since in each topic the following themes were identified:

At the basic level, where the corresponded topics are: (i) Social Skills; (ii) Working Relationships; (iii) Creative Skills, the following modules were defined: a) Empathy; b) Communication; c) Collaboration; d) Growth Mindset; e) Critical Thinking; f) Managing Learning; g) Self-Confidence; h) Work Ethic; i) Receptiveness to feedback; j) Body Language; k) Active Listening; I) Workplace Etiquette; m) Creative Writing; n) Open-Mindedness; o) Creative Thinking. These were the most relevant topics and identified by the focus group.

At the intermediate level, where corresponded topics are: (i) Pedagogical Skills; (ii) TeamWork and Collaboration; (iii) Emotional Intelligence, the following modules were defined: a) Dynamism; b) Development Situation; c) Relation Contexts; d) Professional Development; e) Career Guidance; f) Communication; g) Conflict Management; h) Reliability; i) Respectfulness; j) Self-Awareness; k) SelfRegulation; I) Motivation; m) Empathy. These were the most relevant topics and identified by the focus group.

Finally, at the advanced level, where the corresponded topics are: (i) Digital Literacy Skills; (ii) Community Building and Networking; (iii) Cultural Awareness, the following modules were defined: a) Information and Data Literacy; b) Communication and Collaboration; c) Digital Content Creation; d) Safety; e) Problem Solving; f) Public Speaking; g) Positivity; h) Focus; i) Social Media; j) Cultural Acknowledgement; k) Cultural Interest. These were the most relevant topics and identified by the focus group.

In short, It is also important to realize that this matrix was based on two frameworks developed by the European Commission, EntreComp[11], dedicated to entrepreneurial areas and themes and DigComp[12], focused on basic digital skills. After this collection and analysis of information, the Levels of Matrix related to the Holistic Model were created to fit the learning and professional component of the inclusive strategy to be implemented.

\section{REFERENCES}

[1] M. McMahon, D.L. Bowring, C. Hatton, "Not such an ordinary life: a comparison of employment, marital status and housing profiles of adults with and without intellectual disabilities", Tizard Learning Disability Review, vol. 24, no.4, pp. 213-221, 2019. Retrieved from https://doi.org/10.1108/TLDR-03-2019-0014

[2] G.L. Francis, A. Stride, S. Reed, "Transition strategies and recommendations: perspectives of parents of young adults with disabilities", British Journal of Special Education, vol. 45, pp. 277301, 2018. Retrieved from https://doi.org/10.1111/1467-8578.12232

[3] J. Petner-Arrey, A. Howell-Moneta, R. Lysaght, "Facilitating employment opportunities for adults with intellectual and developmental disability through parents and social networks", Disability and Rehabilitation, vol. 38, no.8, pp. 789-795, 2016. Retrieved from https://doi.org/10.3109/09638288.2015.1061605 
[4] J. Andersson, R. Luthra, P. Hurtig, M. Tideman, "Employer attitudes toward hiring persons with disabilities: A vignette study in Sweden", Journal of Vocational Rehabilitation, vol. 43, no.1, pp. 41-50, 2015. Retrieved from https://content.iospress.com/articles/journal-of-vocationalrehabilitation/jvr753

[5] A. Meltzer, S. Robinson, K.R. Fisher, "Barriers to finding and maintaining open employment for people with intellectual disability in Australia", Soc Policy Admin, vol. 54, no.1, pp. 88-101, 2020. Retrieved from https://doi.org/10.1111/spol.12523

[6] United Nation, Youth with Disabilities, Accessed 04 January, 2021. Retrieved from https://www.un.org/development/desa/youth/youth-with-disabilities.html

[7] World Health Organization, "World Report on Disability", 2011. Retrieved from https://www.who.int/publications/i/item/9789241564182

[8] United Nations, "Fact Sheet Employment of persons with disabilities", 2007. Retrieved from https://www.un.org/development/desa/disabilities/resources/factsheet-on-persons-withdisabilities/disability-and-employment.html

[9] B. O'Day, M. Killeen, "Research on the Lives of Persons with Disabilities: The Emerging Importance of Qualitative Research Methodologies", Journal of Disability Policy Studies, vol. 12, no. 1, pp. 9-15, 2002. Retrieved from https://doi.org/10.1177\%2F10442073020130010201

[10] B. A. Block, G.W. Weatherford, "Narrative Research Methodologies: Learning Lessons From Disabilities Research", Quest, vol. 65, no.4, pp. 498-514, 2013. Retrieved from https://doi.org/10.1080/00336297.2013.814576

[11] M. Bacigalupo, P. Kampylis, Y. Punie, G.V. den Brande, "EntreComp: The Entrepreneurship Competence Framework", Luxembourg, Publication Office of the European Union, 2016. doi:10.2791/593884

[12] A. Ferrari, "A framework for developing and understanding digital competence in Europe", Luxembourg, Publication Office of the European Union, 2013. doi:10.2788/52966 